\title{
Toward the personalized and integrative management of voriconazole dosing during COVID-19-associated pulmonary aspergillosis
}

\author{
Brendan Le Daré ${ }^{1,2^{*}}$, Christelle Boglione-Kerrien ${ }^{3}$, Florian Reizine ${ }^{4,5}$, Jean-Pierre Gangneux ${ }^{6}$ and Astrid Bacle ${ }^{1,6}$
}

COVID-19-associated pulmonary aspergillosis (CAPA) has raised concerns about increased mortality, and a consensus has been recently prepared to define and manage this pathology. Voriconazole is currently recommended as first-line therapy for CAPA [1]. Voriconazole is a second-generation triazole antifungal agent extensively metabolized via cytochrome P450 (CYP450) isoenzyme CYP2C19 and, to a lesser extent, CYP2C9 and CYP3A4. Voriconazole exhibits highly variable nonlinear pharmacokinetics and a narrow therapeutic range. In addition, several conditions of critical-care unit patients, including impaired renal or hepatic function, continuous renal replacement therapy, or extracorporeal membrane oxygenation and altered volume of distribution, render plasma drug concentrations difficult to predict, making therapeutic drug monitoring (TDM) a potential key component in the treatment of CAPA. Furthermore, severe COVID-19 patients often receive multiple drugs, increasing the risk of drug-drug interactions [1]. There is growing evidence that the inflammatory state can also alter the metabolism and thus the pharmacokinetics of many drugs [2]. Given the seriousness of the inflammatory states that occur in COVID-19, particularly during "cytokine storms" and the introduction of corticosteroids as an early and efficient strategy, it is essential to study

*Correspondence: brendan.le.dare@chu-rennes.f

${ }^{1}$ Centre Hospitalier Universitaire de Rennes, Service Pharmacie, 35000 Rennes, France

Full list of author information is available at the end of the article their clinical and biological impact. We observed unexpected variations of voriconazole plasma concentrations in COVID-19 patients hospitalized in an intensive care unit (ICU). In the case reported in Fig. 1, after introduction of voriconazole for ARDS-associated CAPA, inflammation markedly influenced the voriconazole trough concentration (VTC). Metabolite ratios (voriconazole $\mathrm{N}$-oxide /voriconazole) were $<0.3$ during the inflammatory period and $>1$ outside the inflammatory period. In addition, the time during which $\mathrm{C}$-reactive protein (CRP) decreased sharply (from 200.9 to $46.8 \mathrm{mg} / \mathrm{L}$ over four days) corresponds to the period of a sharp decrease in the VTC, suggesting a recovery of metabolic function.

We propose an empirical algorithm to optimize the management of measuring VTC of CAPA patients to avoid misdosing (Fig. 2). First, monitoring of inflammation, at least by measuring CRP, is essential before initiation of voriconazole and then regularly to follow its evolution. As CRP levels above $96 \mathrm{mg} / \mathrm{L}$ have been identified as an independent risk factor for voriconazole overdose among hematological patients (Odds Ratio 27; IC 95\% [6-106]), we propose to consider reducing maintenance doses of voriconazole if the CRP level exceeds this threshold [3]. Second, co-administration of other drugs must be carefully followed, first because of the impact of anti-inflammatory drugs, such as corticosteroids, on the inflammatory process, as well as because of potential drug-drug interactions. Because voriconazole is metabolized via CYP2C19, CYP2C9, and CYP3A4, it is among the drugs that are the most frequently associated original author(s) and the source, provide a link to the Creative Commons licence, and indicate if changes were made. The images or other third party material in this article are included in the article's Creative Commons licence, unless indicated otherwise in a credit line to the material. If material is not included in the article's Creative Commons licence and your intended use is not permitted by statutory regulation or exceeds the permitted use, you will need to obtain permission directly from the copyright holder. To view a copy of this licence, visit http://creativecommons.org/licenses/by/4.0/. The Creative Commons Public Domain Dedication waiver (http://creativeco mmons.org/publicdomain/zero/1.0/) applies to the data made available in this article, unless otherwise stated in a credit line to the data. 


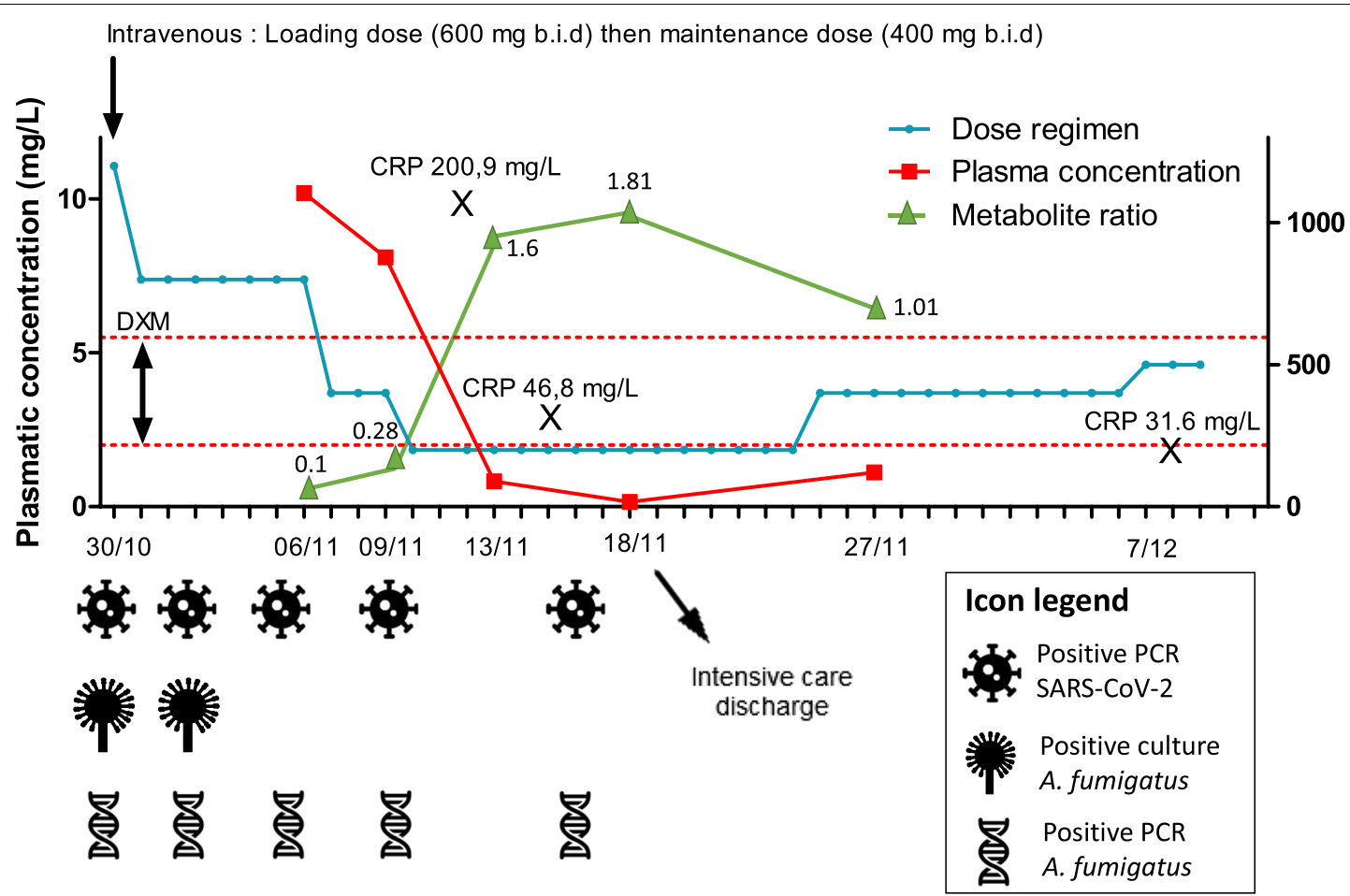

Fig. 1 Biological findings for a COVID-19 patient treated with voriconazole in the context of pulmonary aspergillosis. MR metabolite ratios (voriconazole $\mathrm{N}$-oxide /voriconazole), DXM dexamethasone. The dose regimen of voriconazole is depicted in blue, the voriconazole trough plasma concentration in red, and MR in green. Voriconazole was not administered on the evening of November 10, 2020, nor the morning or evening of November 11, 2020

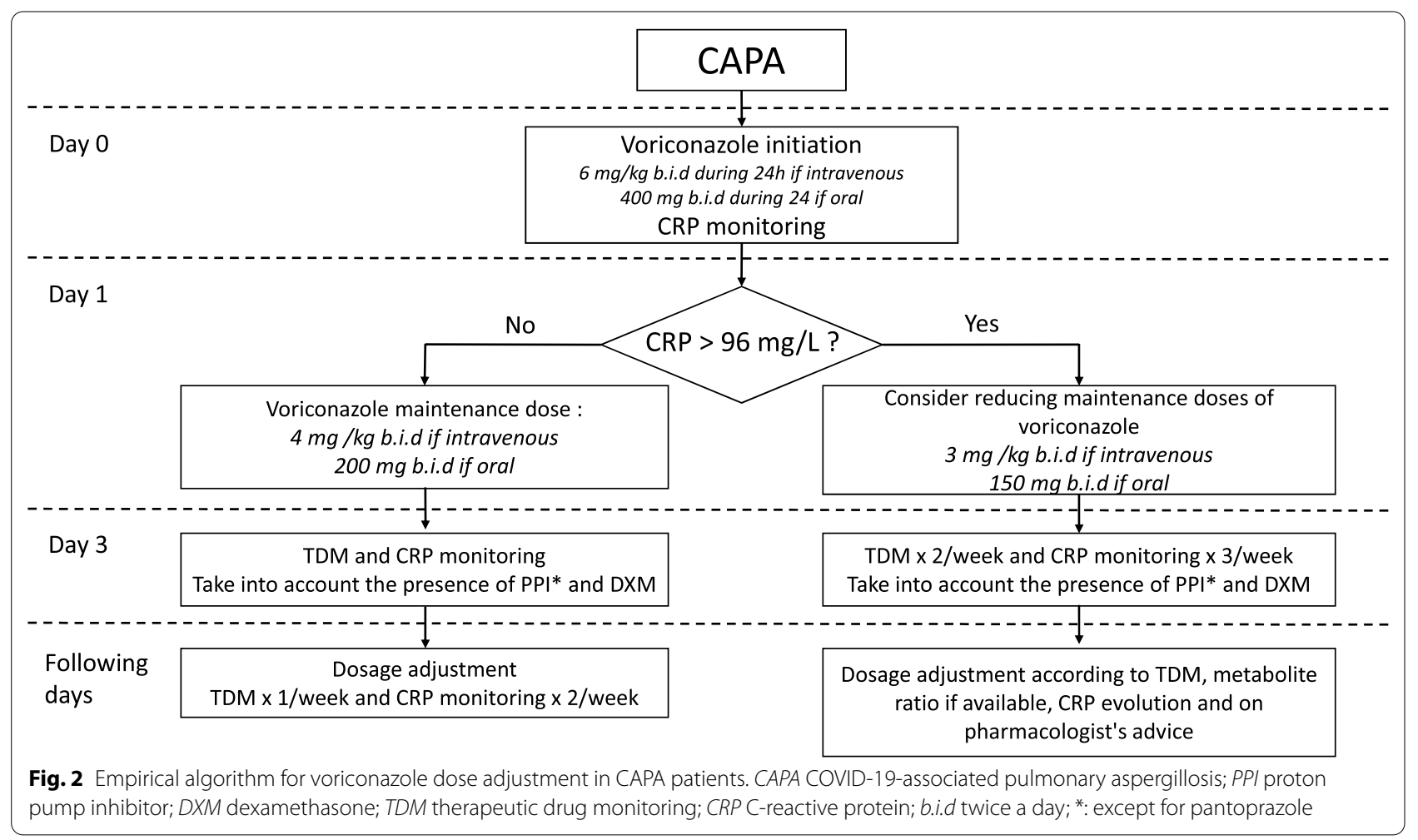


with major drug-drug interactions in the ICU setting [1]. Dexamethasone is now widely used in COVID patients and induces CYP2C9, which could decrease the VTC [4]. In addition, proton-pump inhibitors widely used in the ICU are known to inhibit CYP2C9, CYP2C19, and CYP3A4, and can thus increase the VTC, except for pantoprazole [5]. Lastly, voriconazole TDM is essential for ICU patients, particularly COVID-19 patients, with the aim to maximize efficacy and minimize toxicity. For these reasons, VTC should be performed more frequently while the CRP remains above $96 \mathrm{mg} / \mathrm{L}$, but also when inflammation decreases. Further studies would be needed to assess whether changes in voriconazole protein binding occur during the inflammatory period, as shown for lopinavir [6].

Overall, these findings suggest that therapeutic management must take into account the high level of inflammation of CAPA patients. As it is based on parameters that are readily available in comparison with VTC, the empirical algorithm presented here, that must consider clinical and biological parameters of each patient, could be considered with the goal of improving patient management.

\section{Abbreviations \\ CAPA: COVID-19-associated pulmonary aspergillosis; CYP450: Cytochrome P450; DXM: Dexamethasone; PPI: Proton pump inhibitor; TDM: Therapeutic drug monitoring; VTC: Voriconazole trough concentration.}

\section{Acknowledgements}

The authors thank Alex Edelman's Company for English-language revision and Pr Yannick Malledant for critical comments.

\section{Authors' contributions}

BLD participated in the design of the study, analyzed and interpreted the data and wrote the first draft of the article. AB participated in the design of the study, analyzed and interpreted the data and wrote the first draft of the article. JPG participated in the design of the study, analyzed and interpreted the data and wrote the first draft of the article. CBK analyzed and interpreted the data. All authors read and approved the final manuscript.

\section{Funding}

This research did not receive any specific grant from any funding agency in the public, commercial or not-for-profit sector.

\section{Availability of data and materials}

The datasets used and/or analyzed during the current study are available from the corresponding author on reasonable request.

\section{Declarations}

\section{Ethics approval and consent to participate}

Ethical approval was waived in view of the retrospective nature of the study, and all the procedures being performed were part of the routine care.

\section{Consent for publication}

Written informed consent was obtained from the patient for publication.

\section{Competing interests}

The authors declare that they have no competing interests.

\begin{abstract}
Author details
${ }^{1}$ Centre Hospitalier Universitaire de Rennes, Service Pharmacie, 35000 Rennes, France. ${ }^{2}$ INSERM, INRAE, CHU Rennes, Institut NuMeCan (Nutrition, Metabolisms and Cancer), Réseau PREVITOX, Univ Rennes, Rennes, France. ${ }^{3}$ Department of Clinical and Biological Pharmacology and Pharmacovigilance, Pharmacoepidemiology and Drug Information Centre, Rennes University Hospital, 35033 Rennes, France. ${ }^{4}$ Service des Maladies Infectieuses et Réanimation Médicale, CHU Rennes, 35033 Rennes, France. ${ }^{5}$ Faculté de Médecine, Biosit, Université Rennes 1, 35043 Rennes, France. ${ }^{6}$ Inserm, EHESP, Irset (Institut de Recherche en Santé, environnement et travail) - UMR_S 1085, CHU Rennes, Univ Rennes, 35000 Rennes, France.
\end{abstract}

Received: 1 February 2021 Accepted: 5 April 2021

Published online: 20 April 2021

\section{References}

1. Koehler P, Bassetti M, Chakrabarti A, Chen SCA, Colombo AL, Hoenigl M, et al. Defining and managing COVID-19-associated pulmonary aspergilIosis: the 2020 ECMM/ISHAM consensus criteria for research and clinical guidance. Lancet Infect Dis. 2020;2020:S1473309920308471.

2. Stanke-Labesque F, Gautier-Veyret E, Chhun S, Guilhaumou R. Inflammation is a major regulator of drug metabolizing enzymes and transporters: consequences for the personalization of drug treatment. Pharmacol Ther. 2020;215:107627.

3. Gautier-Veyret E, Truffot A, Bailly S, Fonrose X, Thiebaut-Bertrand A, Tonini $J$, et al. Inflammation is a potential risk factor of voriconazole overdose in hematological patients. Fundam Clin Pharmacol. 2018;fcp.12422.

4. Imataki O, Yamaguchi K, Uemura M, Fukuoka N. Voriconazole concentration is inversely correlated with corticosteroid usage in immunocompromised patients. Transpl Infect Dis. 2018;20:e12886.

5. Yan M, Wu Z-F, Tang D, Wang F, Xiao Y-W, Xu P, et al. The impact of proton pump inhibitors on the pharmacokinetics of voriconazole in vitro and in vivo. Biomed Pharmacother Biomed Pharmacother. 2018;108:60-4.

6. Stanke-Labesque F, Concordet D, Djerada Z, Bouchet S, Solas C, Mériglier E, et al. Neglecting plasma protein binding in COVID-19 patients leads to a wrong interpretation of lopinavir overexposure. Clin Pharmacol Ther. 2021;109:1030-3.

\section{Publisher's Note}

Springer Nature remains neutral with regard to jurisdictional claims in published maps and institutional affiliations. 